WIELKIE TEMATY KULTURY W LITERATURACH SŁOWIAŃSKICH

Slavica Wratislaviensia CLXXIII • Wrocław 2021 •AUWr No 3986

https://doi.org/10.19195/0137-1150.173.1

Data przesłania artykułu: 2.09.2019

Data akceptacji artykułu: 4.10.2019

\title{
TATIANA AKIMOVA
}

Mordowski Uniwersytet Państwowy im. N. P. Ogariowa, Rosja

\section{Память как окультуривание чувства в любовных элегиях Александра Сумарокова}

Современное изучение темы памяти в русской литературе XVIII века проходит по нескольким направлениям: 1) как смена исторического канона, утверждающего движение от времени сакрального к профанному, в литературе (Игорь Павлович Смирнов ${ }^{1}$ ), в которой память предстает как изменение точки зрения в процессе секуляризации культуры (Александр Михайлович Панчен$\left.\kappa^{2}\right)$; 2) как культурологический поворот от Ренессанса к Просвещению, когда ,Человек Просвещения обрывал корни, считал, что история кончена или близка к завершению"3 (Юрий Михайлович Лотман), а, соответственно, память выступала культурным кодом - звеном, сцепляющим разорванные связи; 3) как „память сердца”, которой только предстояло сформироваться при развитии в литературе любовных мотивов (Лидия Ивановна Сазонова ${ }^{4}$ ).

Тема памяти ностальгически звучит в Элегиях любовных (1774) Александра Петровича Сумарокова, которые становятся новым словом в изображении мотивов любви в творчестве писателя-классициста. Классицизм, как извест-

* Исследование выполнено при финансовой поддержке РФФИ в рамках научного проекта № 18-012-00452 „Екатерина II: личность, творчество, эпоха. Энциклопедический словарь”.

1 См. И. П. Смирнов, Олитературенное время. (Гипо) теория литературных жанров, Санкт-Петербург 2008.

2 См. М. А. Панченко, Парадоксы русской истории, Санкт-Петербург 2012.

3 См. Ю. М. Лотман, Архаисты-просветители, [в:] idem, Русская литература и культура. Просвещения, Москва 2000, с. 242.

4 См. Л. И. Сазонова, Освоение языка куртуазности и науки галантного поведения, [в:] eаdeт, Память культуры. Наследие Средневековья и барокко в русской литературе Нового времени, Москва 2012. 
но, не признавал исторической перспективы. Классицистический образ монументален, величествен, статичен, пленяет и завораживает своим спокойствием и неизменяемостью. На этом зиждется его образцовость, правильность, гармоничность: память подчиняется этой заданной модели восприятия классицистического образа. Не случайно миф о золотом веке как вечном, неизменном, блаженном состоянии человечества, - появляется в России в XVIII веке и связывается прежде всего с классицистической идеологией. Золотой век это время, когда нет прошлого и будущего, а есть одно настоящее. Такими же статичными свойствами характеризовалась и эмоциональная память, так как явить обществу внутренние психологические переживания воспринималось моветоном ${ }^{5}$. Когда в середине XVIII века утверждается миф о золотом веке русского дворянства, в это же время в сочинениях Сумарокова появляется идея об утраченном рае, которая актуализирует тему памяти как ценностного понятия, как свойство личностного отношения к произошедшему событию. Именно подобное явление можно наблюдать, анализируя „Любовные элегии”.

Язык любви формировался в российской поэзии XVIII века очень сложно, не имея собственной традиции, постоянно искал опоры то в поэзии немецкой, то во французской, но в большей мере ожидая воплощения в бытовом поведении молодого дворянства, о чем свидетельствовали уроки в Шляхетском Сухопутном корпусе. Его выпускники - не только Сумароков, но и Александр Васильевич Храповицкий, - своими сочинениями демонстрировали русской публике поведенческий канон героя-любовника, сложившийся во французском салоне ${ }^{6}$.

По словам Л. И. Сазоновой, пародирование галантных нравов Жаном Франсуа Дрё дю Радье в Любовном лексиконе (1741), который в 1768 году с французского перевел для русских читателей Храповицкий, могло прийтись по вкусу как молодым девушкам, вступающим на путь поиска возлюбленного, так и кавалерам, желающим познать поэзию любви. Поскольку данный текст, по нашему мнению ${ }^{7}$, стал ориентиром для Сумарокова, то необходимо рассмотреть, как тема памяти была представлена в данном произведении.

В словаре Дрё дю Радье нет статьи о памяти как таковой, что предсказуемо с позиции классицистической эстетики, но есть толкования понятий „вечность”, „времяпровождение”, „годы”, „минуты”, а это значит, что авторы галантной литературы не относились к теме памяти индифферентно, более того, все, связанное со временем, подключалось к игре, рождающейся в отношениях между мужчиной и женщиной.

5 А. Л. Зорин, Появление героя: Из истории русской эмоциональной культуры конца ХVIII-начала ХIX века, Москва 2016, с. 32-33.

6 Т. И. Акимова, Салон Екатерины II и франиузские салоны эпохи просвещения: преемственность и принципиальные новачии, [в:] еаdет, Е. Р. Дашкова и Екатерининская эпоха: культурный фундамент современности, Москва 2011, с. 215-225.

7 Т. И. Акимова, Галантный лексикон „Любовных элегий” А. П. Сумарокова, „Известия Уральского Федерального университета, серия 2: Гуманитарные науки” 2018, т. 20, № 1, с. 30-37.

Slavica Wratislaviensia 173, 2020

(C) for this edition by CNS 
Так, автор иронизирует над понятием „вечность”, которая, как сообщается, „в любовных обращениях гораздо покороче той, которая конца не имеет”, и подчеркивает дистанцию между риторической культурой любовного письма и реальными взаимоотношениями двух людей. Вечность, существующая в клятвах, по заверению французов, длится не более четырех недель, - и этот культ мимолетности, беспамятства и мига в любви будет утверждаться нормой в поэзии и аномалией в жизни.

О том, что восприятие времени писателями рококо меняется по истечению классицистического канона, свидетельствует высказывание о „времяпрепровождении”: „Вся наша жизнь состоит в провождении времени”, однако афористичность фразы недостаточно полно отражает контраст между реальностью и литературой, поэтому автором приводится стихотворение, которое Храповицкий переводит следующим образом:

Мы на досуге все терзаемся любовью,

Умея в вольности пылать с холодной кровью,

Сама судьба велит нам по стопам вздыхать,

Метаться, мучиться и в рифму умирать ${ }^{10}$.

Такое „театральное” умирание от любви отсылает к куртуазному поведению и знакомству с рыцарской литературой, память о которой только начинала складываться в русской читательской среде. В связи с этим Любовный лексикон Дрё дю Радье из легкого развлекательного чтения во Франции превращался в России в поучительную литературу для юношества, постигающего азы светской жизни.

Выход за рамки развлекательности наблюдается и в статье „годы”, поскольку „любовники о них не много говорят, затем что разговор с молодою особою о ей летах не служит похвалою, старуха почтет за обиду, да и женщине средних лет не очень приятна такая хронология" ${ }^{11}$. Как видим, от безделки, занимательности и практических советов по поведению молодого человека в светском обществе книга Дрё дю Радье ведет читателя к формированию просветительского мировоззрения, к философствованию о быстроте человеческой жизни.

Это подтверждается статьей об еще одной единице времени, о которой сообщается, что „Минуты не меньше драгоценны в любви, как часы в военных действиях" 12 , поскольку именно они открывают путь к пониманию тайн человеческих переживаний. А. В. Храповицкий подтверждает это переводом стихотворных строк:

8 Ж.-Ф. Дрё дю Радье, Любовный лексикон, пер. А. В. Храповицкий, Санкт-Петербург 1768, c. 13.

\footnotetext{
9 Ibidem, c. 17.

${ }^{10}$ Ibidem.

11 Ibidem, c. 19-20.

12 Ibidem, c. 40.
} 
Когда всю внутренность жар тайный наполняет

И сладостная мысль рассудок затмевает ${ }^{13}$.

Пожалуй, эти строчки могут служить прологом к любовным элегиям Сумарокова, которые станут реализацией сюжета борьбы разума и стихии, вследствие чего и возникает тема памяти как значимого, ценностного осмысления любовного переживания, причем автор привносит в эту элегию театральные и даже романные приемы с целью максимального воздействия на читателя. Если смысловым ядром жанра элегии является жалоба о любви к женщине или к миру в целом, то „элегического поэта ценят постольку, поскольку в его стихах выразилась его душа, причем душа страдающая и сострадающая"14. Это состояние героя любовных элегий - не просто страдающего, а безумствующего, аффектирующего и доходящего до исступления изображается Сумароковым как будто „по кадрам”, с резко очерченной скульптурной позой и афористичной репликой, обращенной к героине.

Память о чувстве как будто составляется, склеивается из множества разбитых кусочков, тем самым пунктирно обозначая путь героя к добродетели осмыслению и принятию случившегося. Изображение эмоций, страстей, душевного хаоса необходимы автору для подчеркивания идеи рационализации, окультуривания представленных всевозможных оттенков любовного чувства. Противостояние культуры природе, столь свойственное просветительству и, по мнению Иоахима Клейна, лишенное в русской литературе XVIII века, поскольку русскому классицизму была неведома культурная усталость ${ }^{15}$, в данном произведении Сумарокова снимается благодаря действию творческой памяти, способной гармонизировать хаос.

Более того, красот природных ландшафтов как таковых в любовных элегиях нет, за исключением перечислений общих мест, которые нужны лишь для того, чтобы подчеркнуть замещение пейзажа для героя красотой любимой женщины:

С утра до вечера покойной ночи жду.

Хожу, таская грусть, чрез горы, долы, рощи,

И с нетерпением желаю темной нощи:

Брожу по берегам и прохожу леса,

Нечувственна земля, не видны небеса;

Повсюду предо мной моей любезной очи ${ }^{16}$.

13 Ibidem, c. 40.

14 В. А. Мильчина, Франиузская элегия конца XVIII-первой четверти XIX века, [в:] eadem, Франиузская элегия XVIII-XIX вв. в переводах поэтов пушкинской поры, Москва 1989, c. 15 .

15 И. Клейн, Пути культурного импорта. Труды по русской литературе ХVIII века, Москва 2005 , с. 71.

16 А. П. Сумароков, Оды торжественныя. Елегии любовныя. Репринтное воспроизведение сборников 1774 года, Москва 2009, с. 6. 
Благодаря этому приему читатель быстрее погружается в природные страсти, кипящие в душе лирического героя вследствие расставания с возлюбленной. Его сознание открыто всем искушениям:

1) ревности -

Неверная! Меня ты вечно погубила:

А мне казалось, что ты меня любила ${ }^{17}$;

2) терзаниям от упреков возлюбленной -

Сказала мне: как ты расстанешься со мною,

И будешь полонен любезною иною,

Я буду по тебе терзатися, стеня,

А ты, ее любя, не вспомнишь про меня ${ }^{18}$;

3) смертельной тоске -

Когда, тебя хотя, я в мысли нареку,

В минуту ону все я скорби привлеку:

Прошедши радости на память возвратятся,

И слезы из очей неволей покатятся ${ }^{19}$;

4) желанию умереть с именем возлюбленной на губах -

Так знай, любезная, что шествуя к покою, и разлучаяся со жизнью и с тоскою, не смертью, но тобой, я душу возмущу:

И с именем твоим дух томный испущу ${ }^{20}$;

5) безразличию к окружающему миру -

Дни красные весны природу обновляют,

И очи жителей земных увеселяют:

Не веселятся тем мои глаза одни ${ }^{21}$.

Все вместе эти искушения создают картину многочисленных испытаний на пути героя к добродетели - душевному спокойствию, умиротворению, а также гармоничному сосуществованию с возлюбленной. Сама картина пути к гармонии рисуется пунктирно в виде застывших поз героя, запечатленных в его памяти либо вместе с любимой женщиной:

Как слышу, что струи журчат и воды льются,

Вокруг мя новые сметения виются.

Во изумлении услыша водный шум,

Любезну привожу неволею на ум².
17 Ibidem, c. 13.
18 Ibidem, c. 3.
19 Ibidem, c. 10.
${ }^{20}$ Ibidem, c. 9.
21 Ibidem, c. 12
22 Ibidem, c. 7.

Slavica Wratislaviensia 173, 2020

(C) for this edition by CNS 
Либо автором изображается поза невыносимого одиночества героя, мучительно воспринимающего реальность отсутствия любимого человека:

Проснуся я ловлю ея пустую тень,

И осязая мрак, желаю, чтоб был день:

Лишася сладка сна и маяся слезами

Я суетно ищу любезную глазами ${ }^{23}$.

Еще один унылый образ — это уже застывшая поза возлюбленной на могиле героя с его просьбой к ее памяти:

Вздохни, вообразив, как рок меня губил,

И молвь: я помню то, что он меня любил ${ }^{24}$.

Таким образом, путь героя к гармонии оказывается дорогой к индивидуальной творческой памяти, способной конструировать, воссоздавать из хаоса страстей застывшие печальные картины, овеянные теплотой и сочувствием. Этот переход от чувства к сочувствию возникает именно в памяти героя и служит тем базисным элементом новой светской культуры, к которой обращаются писатели-просветители — и А. В. Храповицкий, и А. П. Сумароков.

Ценность для любовников временных промежутков, о которых говорится в Любовном лексиконе, подчеркивается Сумароковым неоднократно, с этого действия памяти начинаются элегии:

Как буду разлучен, на что тогда взгляну,

Я всем тебя, я всем, драгая, вспомяну ${ }^{25}$.

Этим мотивом индивидуальной памяти героя, сознающим красоту возлюбленной, они и заканчиваются:

Не раз, но многажды о мне тогда вспомянешь,

и будешь вображать не редко те часы,

Как были в области моей твои красы ${ }^{26}$.

И все же для работы памяти самым точным инструментом, воспроизводящим остроту чувства, оказываются минуты:

Минуты радостны твоих возлюбленнейших дней,

Не выйдут никогда из памяти моей ${ }^{27}$.

Минута становится для Сумарокова синонимом не времени, а преображения чувства, элементом культурного действия памяти, когда природное существо - человек - превращается в существо добродетельное, смиряя свои страсти:

\footnotetext{
23 Ibidem, c. 6.

24 Ibidem, c. 16.

25 Ibidem, c. 3.

26 Ibidem, c. 17.

27 Ibidem, c. 8.
}

Slavica Wratislaviensia 173, 2020

(C) for this edition by CNS 
В минуту я когда сержусь, как лютый лев,

$\mathrm{B}$ нежнейшую любовь преходит пущий гнев ${ }^{28}$.

Воспитательное действие памяти на героя Сумароков осуществляет переносом из прошлого в настоящее путем рационального осмысления красоты чувства, которое облагораживается с возрастанием временной дистанции, когда память о любви оказывается красивее реальных забав и веселий с возлюбленной:

Уже ушли от нас играния и смехи;

Предай минувшия забвению утехи!

Пусть буду только я крушится в сей любви,

А ты в спокойствии и в радостях живи! ${ }^{29}$

Понимание героем своего преображения под действием памяти воспроизводится Сумароковым при помощи антитезы тело-душа. Миги радостей жизни сопровождаются картинами телесного богатства: автор упоминает о губах, поцелуях возлюбленной, а также о ее груди, чтобы обозначить необходимый рокайльный контекст взаимоотношений мужчины и женщины:

Ты только для тово любовь уничтожаешь,

Что сладости ея себе не воображаешь;

Вкуси, любезная, вкуси любовну страсть! ${ }^{30}$

Другой ценностной координатой становится отказ от страсти в пользу памяти о душе возлюбленной:

Я все спокойствие мое тобою рушу:

Хотя тебя не зрю, люблю тебя как душу ${ }^{31}$.

Подобное преображение героя, от человека, любившего телесные радости и пылавшего страстью до нашедшего успокоение в памяти о нем возлюбленной, - позволяет говорить о представленном в любовных элегиях процессе преображения чувства под действием памяти. Тем самым не только обозначалась перспектива „прошлое-настоящее”, но и утверждалась новая модель поведения героя, принадлежавшего культурному/светскому обществу и для которого память сердца оказывается такой же значимой ценностной координатой, как и воспитание, образование и возможность свободного творчества.

\section{Библиография}

Akimova T. I., Galantnyj leksikon „Lûbovnyh èlegij” A. P. Sumarokova, „Izvestiâ Ural'skogo Federal'nogo universiteta, seriâ 2: Gumanitarnye nauki” 2018, t. 20, № 1 .

\footnotetext{
28 Ibidem, c. 7.

29 Ibidem, c. 11.

30 Ibidem, c. 15

31 Ibidem, c. 11.
} 
Akimova T. I., Salon Ekateriny II i francuzskie salony èpohi prosveŝeniâ: preemstvennost' i principial'nye novacii, [v:] eadem, E. R. Daškova i Ekaterininskaâ èpoha: kul'turnyj fundament sovremennosti, Moskovskij gumanitarnyj institut im. E. R. Daškovoj, Moskva 2011.

Drë dû Rad'e Ž.-F., Lûbovnyj leksikon, per. A. V. Hrapovickii, Sankt-Peterburg 1768.

Zorin A. L., Poâvlenie geroâ. Iz istorii russkoj èmocional'noj kul'tury konca XVIII-načala XIX veka, Novoe literaturnoe obozrenie, Moskva 2016.

Klejn I., Puti kul'turnogo importa. Trudy po russkoj literature XVIII veka, Âzyki slavânskoj kul'tury, Moskva 2005.

Lotman Û. M., Arhaisty-prosvetiteli, [v:] idem, Russkâ̂ literatura i kul'tura. Prosveŝeniâ, Ob"edinennoe gumanitarnoe izdatel'stvo, Moskva 2000.

Mil'čina V. A., Francuzskaâ èlegiâ konca XVIII-pervoj četverti XIX veka, [v:] idem, Francuzskaâ èlegiâ XVIII-XIX vv. v perevodah poètov puškinskoj pory, Raduga, Moskva 1989.

Pančenko M. A., Paradoksy russkoj istorii, Soûz pisatelej Sankt-Peterburga: OOO Žurnal „Zvezda”, Sankt-Peterburg 2012.

Sazonova L. I., Osvoenie âzyka kurtuaznosti i nauki galantnogo povedeniâ, [v:] eadem, Pamât' kul'tury. Nasledie Srednevekov'â i barokko v russkoj literature Novogo vremeni, Rukopisnye pamâtniki Drevnej Rusi, Moskva 2012.

Smirnov I. P., Oliteraturennoe vremâ. (Gipo) teoriâ literaturnyh žanrov, RHGA, Sankt-Peterburg 2008.

Sumarokov A. P., Ody toržestvennyâ. Elegii lûbovnyâ. Reprintnoe vosproizvedenie sbornikov 1774 goda, $\mathrm{Ob}^{\prime}$ edinennoe gumanitarnoe izdatel'stvo, Moskva 2009.

\section{Memory as a Process of Transforming Feelings in Alexander Sumarokov's Love Elegies}

Summary

The article analyses Alexander Petrovich Sumarokov's love elegies in relation to the motif of "memory of the heart" in Russian literature of the 18th century. The aim of the work was to compare the Russian translation by Alexander Khrapovitsky A Dictionary of Love by the French writer Jean-François Dreux du Radier with the Sumarokov elegies. The author points out that this work, out of light entertainment in France, became an enlightening reading for the young generation in Russia, dealing with issues of social life and memory and feelings. The translation of Dreux du Radier's work for Sumarokov became an inspiration, and his love elegies can be called a kind of continuation, according to the author, this continuity is expressed in the choice of words related to the theme of memory - eternity, years, hours, minutes. The latter, in particular, express the value of human life according to Sumarokov - both strong feelings and the memory of them later, when over time human passions are mitigated, which allows to talk about the process of transformation under the influence of the memory of feelings presented in love elegies.

Keywords: individual memory, love elegies, education, A. P. Sumarokov, Rococo

Slavica Wratislaviensia 173, 2020

(C) for this edition by CNS 


\section{Pamięć w procesie przekształcania uczuć w elegiach miłosnych Aleksandra Sumarokowa}

\section{Streszczenie}

W artykule analizie poddano miłosne elegie Aleksandra Sumarokowa w odniesieniu do motywu ,pamięci serca” w rosyjskiej literaturze XVIII wieku. Celem pracy było porównanie rosyjskiego przekładu autorstwa Aleksadra Hrapovickogo Miłosnego leksykonu francuskiego pisarza Jean-François Dreux du Radier z elegiami Sumarokowa. Autorka wskazuje, że utwór ten, przykład lekkiej rozrywki we Francji, w Rosji stał się lekturą dydaktyczną dla młodego pokolenia, poruszającą kwestie życia społecznego oraz pamięci i uczuć. Tłumaczenie dzieła Dreux du Radier stało się dla Sumarokowa natchnieniem, a jego elegie miłosne można nazwać niejako kontynuacją francuskiego utworu. Owa ciągłość wyraża się — zdaniem autorki — w doborze słów związanych z tematem pamięci, takich jak: wieczność, lata, godziny, minuty. Zwłaszcza te ostatnie podkreślają według Sumarokowa wartość ludzkiego życia, zarówno silnych uczuć, jak i pamięci o nich, kiedy z czasem następuje uspokojenie ludzkich namiętności. To pozwala mówić o procesie przekształcania się pod wpływem pamięci uczuć przedstawianych w elegiach miłosnych.

Słowa kluczowe: pamięć indywidualna, miłosne elegie, edukacja, Aleksandr Sumarokow, rokoko 